\section{A 佃emontztration}

\author{
OF
}

\section{SOME EXPERIMENTS ON THE NATURE AND SPECIFIC TREATMENT OF HAY FEVER.}

Bx Sir FELIX SEMON, C.V.O., M.D., F.R.C.P., Physician Extraordinary to His Majesty the King.

IN November, 1902, Professor W. P. Dunbar, the Director of the State Institute for Hygiene of Hamburg, published a pamphlet on the Cause and Specific Treatment of Hay Fever, ${ }^{1}$ in which he reported the results of his investigations concerning that troublesome affection. He had succeeded in isolating from the pollen of certain grasses a toxic substance which, when applied in very small quantities to the eyes or nostrils of people predisposed to hay fever, had within a few minutes produced in a more or less marked degree the local symptoms characteristic of hay fever, whilst the same quantity of the toxin when applied to the eyes or nostrils of persons not pre. disposed had remained without any effect.

Further, he had succeeded, by injecting the pollen of rye, maize, and several other grasses into the circulation of various animals (rabbits, goats, and horses) in producing an antitoxin which, when applied to the ejes or nostrils of hay-fever patients in whom the local symptoms of hay fever had been artificially produced by the previous injection of the toxin, immediately quelled the subjective symptoms, and alter a few minutes caused retrogressive changes in the objective symptoms, produced by the toxin.

These are the principal results-speaking from the practical point of view only-so far obtained by Professor Dunbar though his communication, which has been recently followed by a second, ${ }^{2}$ teems with other interesting points. Thus I may mention that whilst the pollen of twenty-one different kinds of grasses have so far been found to contain the toxic substance producing hay fever, the pollen of roses, limes, wormwood, and other plants, which have been, and are still, frequently accused of causing hay fever in those specially predisposed, have been found by Professor Dunbar to be inactive. It is not the ethereal oils contained in the pollen which produce the typical symptoms. Professor Dunbar has obtained from the pollen three different products: (I) The true toxic substance, (2) a starchy matter, and (3) the ethereal oils, and only the first named (which he has isolated in the form of a white powder) produces the typical symptoms, whilst the ethereal oils, although they have a certain irritating smell, are deficient in toxic properties. His most recent researches lead him to believe that the toxic substance is a proteid, as it gives the characteristic proteid reactions. Finally, it appears from his investigations that it is not the spicula, as had also been surmised, of certain pollen which mechanically produce the irritation, inasmuch as the pollen of the grasses in question have absolutely smooth surfaces. For further details concerning these and similar points, I must refer to Professor Dunbar's original communication, which it may fairly be hoped will soon be published in an English translation.

At the present stage of the investigations it appeared desirable to Professor Dunbar that his researches should be controlled by other independent observers, and with this object in view he was good enough not only to send me small quantities of both the toxin and the antitoxin, but to depute his assistant, Dz. Carl Prausnitz, to help me in the experiments which I now report. I take this opportunity of expressing both to him and to Dr. Prausnitz, my sincere thanks for their kindness.

The toxin was, I understand, produced by extracting crushed maize-pollen with saline solutions at body temperature for about six hours, and by precipitating the toxin with alcohol. The antitoxin was obtained by injecting horses with this extract. Many horses were, however, found refractory, and the best results were obtained from young thoroughbreds.

The experiments in question wore performed on March Igth in the presence of and with the kind co-operation of Dr. Prausnitz, Mr. Lanyon Owen, Mr. Armour, Dr. E. Law, Mr. Louis Taylor, Dr. Tilley, Mr. Waggett, and my eldest son.

On the six last-named gentlemen and myself control 5 experiments were undertaken, whilst the two first-named, who are victims of hay fever, very kindly al owed a complete series of experiments to be performed on them. In addition to them, three patients of my own-Miss C.. Miss $\mathbf{K}$., and $\mathbf{M r}$ R. S.-were sufficiently animated by love of science, if not by the hope of being ultimately relieved of their troublesome affection, to submit to the by no means very agreeable experiments, and to all of them I hereby tendtr my sincerest thanks.

The experiments began by the instillation by means of a pipette of one drop of a solution of the toxin ( 1 in $1, \infty 00$ of normal saline solution), to which was added $\frac{1}{4}$ per cent. of carbolic acid, into the left eye of the seven gentlemen on whom the control experiments were to be performed. The general effect in all of them was, with two exceptions, which will be presently referred to more fully, absolutely negative. A momentary sensation of irritation which occurred in a few instances immediately after the injection, was no doubt due to the addition of the carbolic acid, and invariably passed away in a few seconds.

It was different in the case of Dr. T.; he after a few minutes complained of a feeling of itching and burning in the injected eye, the caruncle began to swell, the lower lid became considerably congested, and the conjunctival vessels were markedly suffused. These sensations persisted for about half an hour, and then gradually disappeared.

It was at first thought that it was perhaps not quite fair to judge from this case, inasmuch as the gentleman in question not merely suffers, although only very occasionally, from asthma when residing in certain localities, but also that, as he stated, the mucous membranes of his eyes and nose are extremely sensitive to wind and dust, particularly when riding or cycling, a statement very frequently made by hayfever patients. It seemed, therefore; by no means impossible that his case was one of greater susceptibility to the poison of hay fever than those of ordinary non-predisposed persons.

Another suggestion, however. was made to the effect that the carbolic acid contained in the toxin might have been the source of more lasting irritation. In order to test this further, a control experiment was made on March 2oth, one drop of toxin being instilled into the right eye, and a drop of carbolized water into the other. The characteristic phenomena were produced in that eye only into which the toxin had been instilled. This fact certainly points in the direction of the conclusion that Dr. T., although not an actual sufferer from hay fever, is more susceptible to its poison than the general run of ordinary non-predisposed persons.

The second experiment, which points in'the same direction, refers to my own case. I have never suffered from hay fever, although not infrequently $I$ am liable to sudden violent paroxysms of sneezing, followed by c onsiderable rhinorrhoea, particularly in the early morning at any time of the year. The instillation of the toxin into my left eye had no immediate effect whatever. About six hours after the experiment, however, I was suddenly taker with several very violent fits of sneezing, followed by profuse secretion of watery fluid from my left nostril only, which for a time became almost completely obstructed. At the same time 1 experienced sensations of heat, burning, and soreness in the left half of my nose, all of which were perfectly new to me, whilst in my left eye, a'though it was not congested, I had a feeling as if I had some particles of sand between the upper eyelid and the eyeball. These symptoms lasted until I went to bed at about 11.30 p.m., but had completely disappeared $n \in \mathbf{x t}$ morning. It was certainly remarkable that all the symptoms named were restricted to $m y l \in \mathrm{ft}$ eye and nostril, the toxin having been instilled into the lelt eye.

In order to control this observation, on March 2oth at 6 p.m. a drop of pure toxin was instilled into my right eye. In the course of the evening nothing further happened. Shortly after awakening on March 21st, however, I sneezed a few times, and this was followed by watery secretion from both nostrils, though undoubtedlp more from the right, which for about ten minutes became quite obstructed and then very suddenly quite patent again. There was none of the feeling of heat burning, and soreness which I had experienced in the left half of my nose on the evening of March 2oth. Four or five minutes after the nasal symptoms had quite passed off $I$ suddenly had a little wheezing in my chest, which was quite audible, but passed off within two or thres minutes. The last-named phenomenon is one from which I hardly ever suffer.

Although neither of these exreriments is in any way 
conclusive, it would seem probable that I am-although this has been hitherto unknow'n to me-to some degree susceptible to the influence of the hay-fever toxin, and that the poison without producing at first any local symptoms in the part into which it was instilled, travelled in minute quantities through the naso-lachrymal ducts into the nose, and there, after the lapse of a few hours, produced the characteristic nasal symptoms.

None of the other gentlemen, as I have ascertained by subsequent inquiry, have experienced any after-effects from the instillation of the toxin.

Experiments on Patients Liable to Hay Fever.

I now come to the experiments made with toxin and antitoxin in the five persons suffering at the typical time of the year from hay fever, who kindly submitted to be experimented upon. Owing to Dr. Prausnitz's presence, we had the privilege of not merely experimenting with the artificially produced toxin; but also with actual pollen of maize collected last year, and with some fresh pollen of grasses obtained quite recently at Genoa, and sent- to Professor Dunbar by some hay fever patients, who are now staying in that neighbourhood, aud have just had their first attack this year.

In the following description the exact times at which the experiments were conducted and the sensations and objective symptoms which were recorded are stated, as they were taken down at the time. Several of the medical men present cooperated in controlling these times, and the resu'ts were w ritten down immediately.

CASE I.

Mr. L. O., aged about ${ }_{32}$, has suffered from hay fever practically all his life: His father was similarly affected. He is the only one of several brothers and sisters to whom the tendency has been transmitted. Th attack is quite typical, affecting the eyes and nose, and very occasionally causing asthma. He has been treated in one nostril with the galvanocautery, with practically no effect.

At 2.4 $;$ p.m. one drop of a mixture of equal parts of a toxin solution (r in 1,00$)$ and normal horse serum was instilled into the left eye; into th right eye one drop of a mixture of equal parts of the toxin solution ( $\mathrm{I}$ in $\mathrm{I}, 0: 0)$ and antitoxic serum.

3.5 p.m.-Sensation of heat in left eye, caruncle of left eye beginning to swell and to get reddened, itching begins.

3.10 p.m. - No increase in symptoms.

3. Ir p.m. - Symptoms of heat, etc., increasing.

$3 \times 7^{*} \mathrm{p} . \mathrm{m}$. - Complains (much of heat and discomfort in the left eye. Antitoxin (one drop) instilled into the left eye and practically immediately afterwards the itching improved, but not the feeling of heat.

3.21 p.m.-Heat has disappeared.

3.27 p.m.- Pollen of maize rubbed into the right nostril.

3. 29 p.m.- Itching begins in the tip of the nose.

3.3r p.m.-Irritation increases all round the nose.

3.33 p.m.-Sensation of heat in both eyes, and itching in eyes and nos e.

339 p.m.-More pollen introduced into the right nostril.

3.42 p.m.-Antitoxin (2 drops) inserted in the right nostril.

344 p.m.-Great relief in both eyes and nose.

3.50 p.m.-One drop;of mixture of toxin ( $x$ in 500 ) with equal quantity of normal serum instilled into left eye, and a similar solution with antitoxic serum into right eye.

3.52 p.m.- Sensations of heat and itching in the left eye.

3.53 p.m.-In the left eye pricking and general irritation.

3.54 p.m.-Left caruncle again getting very red. Obstruction in the right nostril. Increased irritation and heat in the left eye.

4.0 p.m. - The throat feels uncomfortable; soreness and irritation. One drop of the antitoxin injected into the left eye, the itching stopped almost immediately.

About 5 p.m. the sensation of heat returned in the left orbit; then the usual headache began and some slight dyspnoea. At 5.45 p.m. a sneezing attack, but not a severe one, began. In the evening the usual feeling of lassitude was experienced, always present in a greater or less degree in the patient's case according to the severity and length of the attack. [The information about these later effects was kindly commnicated to me by letter next morning.]

CASE II

Dr. P., aged 26. Several members of the family have hay fever, and he lias suffered for about fourteen years from genuine hay fever at the typical time with the characteristic symptoms in eyes and nose. He has once had asthma at the close of an unusually severe attack of hay fever. Treatment with the galvano-cautery undertaken seven years ago was successful for two years.

3.6 p.m.-One drop of a mixture of equal parts of a toxin solution ( $x$ in oc). and normal serum was instilled into the left eye; into the right eye i drop of a mixture of equal parts of a toxin solution ( 1 in 500 ) and antitoxic serum. The right eye remained absolutely normal throughout.

3.9 p.m.-In the left eye sensation of burning and itching.

3.ro p.m.- Left caruncle red and swollen.

y.t. p.m.-Caruncle and edge of lower lid of left eye red and much swollen; ; conjunctival vessels injected.

3.29 p.m.-One drop of antitoxic serum injected into the left eye.

3. 30 p.m. - Itching and burning nearly gone.

3.45 p.m.-Swelling and suffusion of left eye decidedly less.
3.37 p.m.-Into the left nostril some maize pollen was introduced. 3. $3^{8}$ p.m.-Tickling sensation in the nose; desire to sneeze. 3.44 p.m.-Patient snuezed once.

3.54 p.m.-Rhinoscopic examination: injection of the left inferior turbtnated bone; watery fluid running down from the middle fossa mucous membrane swollen ; right nostril quite normal.

3.56 p.m.-Increase of nasal symptoms; a good deal of rhinorrhoea, two sneezing attacks, constant desire to sneeze.

After this the symptoms very gradually abated, and at about 4.30 p.m. matters had almost returned to normal conditions.

It ought to be stated here that Dr. P., who has often experimented on himself, informs me that his susceptibility has-at any rate transitorilybeen considerably diminished since, a week ago, $1 \mathrm{c.cm}$. of antitoxin was injected subcutaneously into his left arm.

\section{CASE III.}

Mr. S., aged 28, has for nearly twenty years suffered from genuine hay fever, nose and eyes alone being affected; no hay asthma. It always comes on in June. The nasal mucous membrane, when I saw the patient first (March, I902), was considerably swollen. He submitted to prophylactic galvano-caustic treatment of the nasal mucous membrane in April last, but the result was absolutely negative, the hay fever being as bad as usual last season.

2.57 p.m.-Into the left eye one drop of a mixture of equal parts of a toxin solution ( $r$ in $r, \infty 00$ ) and normal serum was injected; into the right eye one drop of a mixture of equal parts of the toxin solution $(x$ in $1, \infty 00$ ) and antitoxic serum. No irritation felt in either eye.

3.6 p.m. - Into the left eye one drop of a toxin ( $x$ in 500 ) and norma) serum mixture: into the right eye one drop of a toxin ( $x$ in 500 ) and antitoxin mixture.

3.8 p.m.-In the left eye itching, burning, and desire to rub it.

3.1 $\mathrm{r}$. m. - The sensation is passing off.

3.15 p.m.-Conjunctival vessels of left eye much congested. In the right eye a slight feeling of irritation, which passed off quickly.

3.20 p.m. - The patient feels sure that he is suffering from an attack of hay fever.

3.29 p.m.-He has all the ordinary dull feeling of recovery from an attack of hay fever.

$33^{5}$ p.m.-Symptoms practically disappeared,

\section{CASE IV.}

Miss C., aged 2r, has suffered for many years from genuine hay fever at the typical time with the characteristic symptoms in eyes, nose, and chest. She always euffers severely, and was once treated with the galvano cautery with transitory effect.

3 I4 p.m.-Into the left eye one drop of a mixture of equal parts of a toxin solution ( $x$ in $x, c 00$ ) and normal serum was injected; into the right eje one drop of a mixture of equal parts of the toxin solution ( $x$ in $x, 000)$ and antitoxic serum.

3.20 p.m.-Left caruncle red. Conjunctival vessels injected. ; Feeling of irritation in the right eye.

3.25 p.m.-No increase of symptoms. Into the left eye one drop of toxin (x in 500) normal serum mixture; into the right eye one drop toxin $(x$ in 500 ) antitoxin mixture.

$3.3^{2}$ p.m.-In the left eye, feeling of irritation : in the right eye, none.

3.37 p.m. -Into the left eye one drop of antitoxin.

3.39 p.m.-Left nostril rubbed with maize pollen.

3.40 p.m.-Throat getting sore, just like in an ordinary attack.

3.44 p.m. - In the left eye feeling of irritation.

3.45 p.m.-Left nostril rubbed again with maize pollen.

$3.46 \mathrm{pm}$-In the left eye increase of irritation.

349 p.m.-Left caruncle fiery red. One drop of antitoxin into left eye.

3.53 p.m.-One drop of antitoxin into the left nostril.

3.55 p.m.-Patient feels on the whole more comfortable.

4.2 p.m.- Left eye still irritated. One drop of antitoxin.

4.3 p.m. - Irritation in left eye bas ceased.

4.8 p.m.-Rhinoscopic examination : Left nostril completely obstructed mucous membrane over middle turbinated bone so mueh swollen as actually! to touch the septum. Appearance as often seen in genuine hay fever. The right nostril wide open; normal.

4.I I p.m. - Two drops of antitoxin into the left nostril.

Towards the close of this experiment the patient was exceedingly de pressed and presented the characteristic appearance of hay fever patients during a severe attack.

The patient informed me on March eth that she had felt very ill, just as in a typical attack of hay fever during and a little while after the experiment, but that the symptoms had gradually passed off in the course of the evening, and that now she felt quite well again.

Case v.

Miss K., aged 45, was seen in June, 1902, a most typical case of hay fever, very characteristically described by the uncommonly intelligent patient. There is a history of hay fever in other members of the family She herself has suffered for over 20 years with the characteristic sym. ptoms in eye, nose, throat, and chest.

3.22 p.m.-Sniffed up grass pollen recently obtained from Geno3. No result.

3.30 p.m. - Into the left nostril one drop of a toxin solution ( $r$ in 500 ).

3.35 p.m.-Feels a little uncomfortable.

3.36.p.m.-Uncomfortable sensation has increased in both nostrils. 3.38 p.m.-Great desire to sneeze.

$3.4 \mathrm{r}$ p.m.-Into the left eye a mixture of equal parts of torin ( $\mathrm{r}$ in 500 and normal serum; into ihs 1 isht eye one drop of a nixtur, of equal parts of a toxin solution ( $x$ in $5^{-0}$ ) and antitoxic serum. 
4.20 p.m.- Left eye itching; left caruncle much suffused; right caruncle abnormally pale.

4.3 p.m. - Into the right nostril one drop of toxin solution ( $x$ in 500 ). 4.6 p.m.-Itching in the left eye has ceased, the right nostril is beginning to tickle; typical sensation of irritation. Feeling of itching at the back of the soft palate, which increased during the next two minutes.

4.12 p.m. - The patient complained of the frontal headache from which she usually suffers during the hay-fever attack. In the nostril nothing is experienced but the ordinary irritation.

During the afternoon and evening the tickling continued, the patient sneezed twice at 4.45 p.m. again at midnight, and at $8 \mathrm{a} \mathrm{m}$. on the follow. ing morning. In the evening throat, nose, and ear on the right side felt sore and tired, as they do after a bad attack of hay fever. Next morning patient still felt as if she was suffering from a slight summer attack of hay fever.

[Information as to after-effects given by letter, March 2oth.]

CoNCLUSIONS.

From the above experiments the following conclusions, I think, may fairly be drawn

I. There can be no doubt that Professor Dunbar has succeeded in extracting from the pollen of certain grasses (maize, wheat, rye, anthoxanthum odoratum, agropyrum repens, cynosurus cristatus, etc.), a toxin which when instilled into the eyes or nostrils of people predisposed to hay fever, produces in these parts the characteristic subjective and objective symptoms of the disease.

2. The toxin, when injected into the eyes or nostrils of people not predisposed, produced, in the great majority of cases, no symptoms whatsoever, but it certainly appears from Dr. T.'s and my own experiences as if there were instances of transition in which, although the persons experimented upon never suffer from typical hay fever, they are yet more susceptible to the influence of the toxin than the ordinary run of people.

3. The effects of the toxin in people suffering from hay fever are as variable in intensity as are the attacks of the affection itself, both with regard to the local and the constitutional symptoms.

4. Professor Dunbar's antitoxin certainly produced immediate disappearance of the subjective, and after a few minutes great amelioration of the objective symptoms.

5. The mixture in equal parts of a toxic solution ( 1 in 500) and the antitoxic serum suffices to neutralize the specific effects of the toxin.

6. The effects of the antitoxin appear in some instances to be sufficient to prevent a reappearance of the subjective sym ptoms, whilst, in other instances repeated instillations of the antitoxin were required to produce ultimately the return to normal conditions.

It is hardly necessary to add that this can only claim to be a preliminary report on a very interesting and important subject. We are, as it were, on the threshold of facts which if our expectations should be realized, would in many respects open a new era for the better understanding and more efficient treatment of a most troublesome and common disease. At the same time, it cannot be too emphatically stated that all we know at the present is not sufficient to build excessive therapeutic hopes upon, and this for the following reasons:

I. We do not yet know what the nature of the special predisposition is which makes one person react violently to the influence of both the natural pollen and of the artificiallyproduced toxin, whilst it leaves another quite unaffected.

2. Whilst it may be justly hoped that it will be possible to produce an even more effective serum no guarantee can at present be given, nor do we know for certain whether it will be possible to produce such antitoxin in sufficient quantities to use it extensively. It may, however, confidently be hoped that such will be the case.

3. Whilst the antitoxic serum as at present produced quickly neutralizes the local effects of the toxin, it is impossible to foretell-and on this point I wish to insist very strongly-whether in cases of genuine attacks of hay fever, an even more powerful serum than that at present prepared, applied by way of instillation into the affected mucous membranes, or by subcutaneous injection or by internal administration, will arrest all the symptoms when once fully established, and even if it should do so, whether the effect will be lasting, or whether the symptoms may not return.

4. Finally, it is equally impossible to foretell whether by the prophylactic application of a very powerful serum we shall succeed in altogether preventing the actual outbreak of an attack in those specially predisposed.

1 know I am in perfect accord with the original investigator in giving this strong warning against premature hopes which ultimately may not be fulfilled. At the same time, I think there cannot be any doubt that Professor Dunbar has made a very interesting and important discovery, which, it may be devoutly hoped, in the interests of many thousands of suftferers. will ultimately lead to the development of an effectual specific treatment of this very troublesome affection. He has most kindly promised to keep me au courant of his further experiments, and I, too, hope to continue my own researches. When anything new can be reported, I hope to return to the subject.

REFERENCES

1 München and Berlin : R. Oldenbourg. 1903. 2 Weitere Beiträge zur Ursache und speeifischen Heilung des Heufiebers, Deut. med. Woch., 1903 No. ix.

\section{(C)}

\section{THEORIES OF IMMUNITY AND THEIR} CLINICAL APPLICATION.

Delivered at the Royal College of Physicians, London.

By A. S. GRUNBAUM, M.D.Cantab., F.R.C.P., Director of the Cancer Research in University College and the Royal Infirmary, Liverpool: Assistant Physician, Liverpool Hospital for Consumption and Diseases of the Chest.

\section{LECTURE II.}

TheORIES $\odot$ IMMUNITY (continued)

IT is well to recall the fundamental fact on which depends the production of all these bodies or substances which we are about to study. It seems to be a universal physiological reaction of the healthy organism to produce substances more or less specifically antagonistic to alien cells and some cell products. Although it is a familiar fact that tolerance can be established towards some crystallizable poisons, yet the " antidote" thus formed is not of the same nature as when an organized cell product is the poison. Yet it must not be thought that the distinction either lies between colloid and crystalloid, or that the poison or antidote is necessarily of proteid nature. Antidotes have been obtained for crystallized proteids, while attempts to produce them for starch or similar products, also gelatine, have failed. But in the case of gelatine, at any rate, a species of antidote in the form of a gelatinedissolving enzyme is produced.

We have also seen that the antidote is the cast-off link by which the poison attaches itself to the cell. If this link does not exist the poison cannot act on the cell, and there is no need for an antidote.

[The lecturer at this point described a symbolic method devised by Professor $H$. C. Ernst, of Harvard University, ${ }^{1}$ by which the conception of Ehrlich's theory had been found to be assisted.]

In the case of the toxins, the poison is a cell product and the antitoxin merely the antidote to this cell product. But as regards the mode of formation of this antidote there is 8 difference of opinion. Metchnikoff thought, and still thinks, that it may be modified toxin, in spite of the facts that one unit of toxin may lead to the production of about 100,000 units of antitoxin, that its production may be increased by pilocarpin injections, and that immunized animals may by repeated venesections have the whole of their blood withdrawn, and yet at the end supply a serum of nearly the same antitoxic power as at first. Moreover, antitoxin exists normally in demonstrable quantity in the blood of some men and animars-corroborative evidence of Ehrlich's views.

It must be clearly recognized that it is not necessarily one kind of cell which may form antitoxin, although the effects of the toxin may be most evident on one species of cell. Thus the tetanus toxin fixes on the cells most susceptible to it, namely, of the central nervous system. We know this to be so clinically: but it can also be shown in the manner of a chemical experiment. On mixing tetanus toxin with an emulsion of brain substance and then injecting it, it is found to have lost its toxic power. If the mixed toxin and emulsion be centrifugalized, the supernatant fluid has no more toxic power. It is no mere mechanical precipitation, since boiled brain substance has no neutralizing effect. In animals but slightly susceptible to tetanus the fixıng and neutralizing power of the brain substance is correspondingly small. The proof value of these experiments is not affected by the fact that the same result can be obtained with lecithin, cholesterin, etc. 